\title{
The Goldilocks principle and perioperative red blood cell transfusion: Overuse, underuse, getting it just right
}

\author{
Nadia B. Hensley, MD, Charles H. Brown, MD, Steven M. Frank, MD, and \\ Colleen G. Koch, MD, MS, MBA
}

\author{
From the Department of Anesthesiology and Critical Care Medicine, Johns Hopkins Medicine, Baltimore, Md. \\ Received for publication Jan 16, 2019; revisions received Jan 16, 2019; accepted for publication Jan 16, 2019; \\ available ahead of print May 11, 2019. \\ Address for reprints: Colleen G. Koch, MD, MS, MBA, Department of Anesthesiology and Critical Care Medi- \\ cine, Johns Hopkins Medicine, 1800 Orleans St, Bloomberg 6302, Baltimore, MD 21287 (E-mail: ckoch11@ \\ jhmi.edu). \\ J Thorac Cardiovasc Surg 2020;159:971-3 \\ $0022-5223 / \$ 36.00$ \\ Copyright () 2019 by The American Association for Thoracic Surgery \\ https://doi.org/10.1016/j.jtcvs.2019.01.145
}

The Goldilocks principle refers to the children's story in which a character named Goldilocks preferred porridge that was "just right" - neither too hot nor too cold. This principle has been applied to such fields as economics, biology, and more. ${ }^{1}$ In the setting of perioperative decision making regarding when to transfuse red blood cells (RBCs), getting it just right for each specific patient eludes us. Moreover, in the era of precision medicine, we in fact desire to get it just right by taking into account patient-specific factors, such as comorbidity, physiologic milieu, and patient and organ system adaptive responses to acute anemia. We also desire to take into account the specific surgical procedure and dynamic nature of the operating theater, with concurrent blood loss, acute hemodilution, and fluctuations in hemodynamics-all of which can wreak havoc on vulnerable organ systems. Notwithstanding, much of our decision making regarding perioperative RBC transfusion hinges on a hemoglobin trigger value, which may not be just right for every patient.

This current investigation by Mazer and colleagues ${ }^{2}$ is a 6-month follow-up from their multicenter noninferiority trial, ${ }^{3}$ Transfusion Requirements in Cardiac Surgery Trial III (TRICS-III). By way of background, the TRICS-III trial enrolled more than 5000 cardiac surgical patients (the largest of its kind). Patients who were deemed to be at moderate risk for death according to an additive euroSCORE I of 6 or greater were randomly assigned to a restrictive or liberal RBC transfusion strategy. The restrictive strategy was based on a hemoglobin trigger of less than $7.5 \mathrm{~g} / \mathrm{dL}$, and the liberal strategy on a trigger of less than $9.5 \mathrm{~g} / \mathrm{dL}$ in the operating room and intensive care unit (ICU) and less than $8.5 \mathrm{~g} / \mathrm{dL}$ on the post-ICU wards. The primary composite outcome was death or morbidity (myocardial infarction, stroke, and new-onset renal failure requiring dialysis), during the index hospitalization or within 28 days of follow-up. Secondary outcomes included RBC use, duration of postoperative ventilatory support, ICU length of stay, and other morbidity outcomes. The restrictive transfusion strategy was found to be noninferior to the liberal strategy hence,

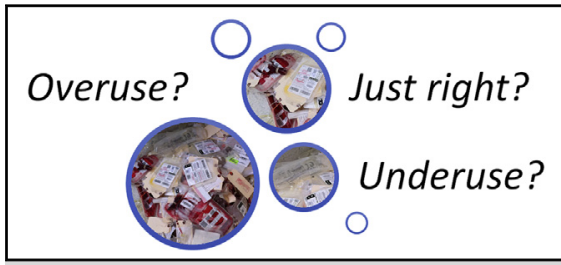

The Goldilocks principle and RBC transfusion: overuse, underuse, just right?

\section{Central Message}

Transfusion when not indicated can be health care waste. The TRICS-III trial provides evidence supporting a restrictive strategy, thereby allowing us to reduce $\mathrm{RBC}$ use and costs and to improve value.

The Invited Expert Opinion provides a perspective on this topic based on the following paper: N Engl J Med. 2018;379:1224-1233. https:// doi.org/10.1056/NEJMoa1808561.

See Commentaries on pages 974 and 976.

so Mazer and colleagues ${ }^{3}$ concluded that a more restrictive transfusion strategy was a safe approach in the cardiac surgical setting.

Results from the 6-month follow up from the TRICS-III trial by Mazer and colleagues ${ }^{2}$ demonstrated that a restrictive strategy was again noninferior to a liberal strategy for the same primary outcome as the original trial and also noninferior for an expanded composite outcome that included readmission, revascularization, or need for emergency department visits. A striking finding of the TRICS-III trial, and contrary to what some clinicians believe, was in the subgroup analysis, which found that a liberal transfusion strategy in older patients $(\geq 75$ years old) had a worse primary outcome in the original trial, and those at least 85 years old had a worse primary outcome at 6-month follow-up. Because half of the patients were at least 75 years old, and about $4 \%$ were at least 85 years old, this finding is both important and interesting. Observational studies have reported that older patients overall have a higher risk for transfusion during surgeryrelated hospitalizations, despite the lack of evidence that there is a benefit. ${ }^{4}$ 
Other trials on transfusion triggers in cardiac surgery ${ }^{5}$ have supported findings of Mazer and colleagues with regard to the noninferiority of restrictive transfusion strategies relative to more liberal approaches, with a few exceptions for secondary outcomes and small subgroups. For example, in the multicenter Transfusion Indication Threshold Reduction (TITRe2) trial, Murphy and colleagues ${ }^{6}$ reported increased risk of 90-day mortality (a secondary outcome) for patients randomly restricted to a restrictive (hemoglobin $<7.5 \mathrm{~g} / \mathrm{dL}$ ) versus liberal (hemoglobin $<9 \mathrm{~g} / \mathrm{dL}$ ) approach. All-cause mortality at 90 days for the restrictive threshold was $4.2 \%$, whereas that for the liberal threshold was $2.6 \%(P=.045) .{ }^{6}$ This finding might not have been significant had a post hoc adjustment for multiple comparisons been performed. The TITRe 2 trial's primary study outcome of serious infection or ischemic events for the more than 2000 randomly allocated patients was similar between groups, as were associated health care costs. ${ }^{6} \mathrm{Na}-$ kamura and colleagues ${ }^{7}$ reported on a substudy of the Transfusion Requirements After Cardiac Surgery (TRACS) trial, ${ }^{8}$ in which restrictive and liberal transfusion strategies resulted in a similar primary composite outcome of 30-day all-cause mortality and severe morbidity. They reported that a restrictive approach was associated with an increased rate of cardiogenic shock (a secondary outcome), however, in the older subgroup of patients $\left(\geq 60\right.$ years of age). ${ }^{7}$

There are differences in trial design among these investigations. For example, the TITRe 2 study differed from TRICS-III ${ }^{2,3}$ and others in that the investigators did not randomly allocate patients until the post-operating room phase of care; patients in the TITRe 2 study had received intraoperative RBC transfusions in $25 \%$ of the restrictive group and in $26 \%$ of the liberal group before randomization. ${ }^{6}$ TRICS- III $^{3}$ and others ${ }^{5}$ randomly assigned patients to restrictive versus liberal groups for the entire continuum of care (operating room, ICU, floor), whereas others confined randomized care to only the intraoperative and ICU settings (excluding the floor). ${ }^{8}$ It is also important to highlight that definitions for what constitutes restrictive and liberal hemoglobin thresholds differ among studies. ${ }^{3,5,6,8}$

These trials provide us with a better understanding of the appropriate use of an expensive resource for which cardiac surgery ranks among the highest of consumers. Transfusing when unnecessary is a form of health care waste, resulting in potential harm along with the increased health care costs associated with transfusion. On the other hand, failing to transfuse when RBCs are needed, exposing patients to extremes of anemia, can also be considered as health care waste, because it results in potentially avoidable morbidity along with the associated cost. Berwick ${ }^{9}$ framed overuse as a quality defect and underuse of care deemed effective yet underused also as a quality defect. He highlighted that the next quality frontier will involve addressing overuse in health care, and to do so will require a research base to enable us better to differentiate useful from wasteful health care. $^{9}$ Trials from Mazer and colleagues ${ }^{2,3}$ and others build on such a proposal by contributing to a research base, enabling us to be better informed with regard to transfusion decisions that may lead to reduced health care waste.

Mazer and colleagues' work $^{2,3}$ also guides us in better defining the floor for what is deemed to be safe practice for lower tolerable hemoglobin levels and above which could be considered non-value added care, or health care waste. Although the literature can help us distinguish wasteful practices, real-world transfusion decisions are often embedded in local tradition and slow to change. We are aware of the wide variation in RBC transfusion practices in cardiac surgery, ${ }^{10}$ despite publication of transfusion practice guidelines. ${ }^{11}$ Lack of adoption of transfusion guidelines ${ }^{12}$ has in part been attributed to lack of sound evidence in the form of randomized, controlled trials to support reducing hemoglobin thresholds ${ }^{12}$ and specifically to the hint of evidence in favor of liberal transfusion mentioned previously for secondary outcomes and subgroups. TRICS-III, being the largest study with 2.5 times the number of patients of any other transfusion trigger trial, along with the longer 6-month follow-up, offers sound evidence to support a restrictive transfusion strategy that, if adopted, will result in potential reductions in unwarranted care. Furthermore, the common belief that elderly patients require more transfusions or a higher hemoglobin level has also been shown to not be true, at least in cardiac surgery.

A unique focus on reducing health care costs was proposed by Berwick and Hackbarth, ${ }^{13}$ who suggested approaching cost reductions by reducing health care waste, that is, non-value added care. Among their 6 categories of health care waste is that of overtreatment. Randomized, controlled trials on transfusion uniformly demonstrate that fewer patients are transfused when randomly allocated to a restrictive transfusion strategy and that overall a restrictive strategy results in a reduction in blood use of approximately a third. ${ }^{3,5,6,8}$ Incremental costs associated with restrictive and liberal transfusion strategies were examined by Stokes and colleagues ${ }^{14}$ in an analysis of the findings from TITRe2 study. A restrictive transfusion strategy was considered more effective and less costly than a liberal approach. ${ }^{14}$ Overall, these studies have provided additional support for our current transfusion practice guidelines, and they allow us to contribute to reducing health care waste by making more informed transfusion decisions that lead to reduced RBC use.

\section{CONCLUSIONS}

"How low can you go?" is a daily question posed by frontline caregivers in the cardiac surgical setting. The answer to the question seeks to balance risk and benefits of transfusion and anemia, while understanding that risks 
may be different for the individual patients and organ systems, as well as recognizing an ability for both to respond adaptively to acute anemia. ${ }^{15,16}$ We currently lack technology to detect anemia-related tissue hypoxia in real time and the influence of the perioperative milieu and patient-specific factors on the overlay of acute anemia. Although we currently are unable to get it "just right" for each individual patient, results from trials such as that of Mazer and colleagues ${ }^{2,3}$ provide us data that will move us further away from overuse and allow us to contribute to reductions in overall health care waste.

\section{Conflict of Interest Statement}

Authors have nothing to disclose with regard to commercial support.

\section{References}

1. Wikipedia. Goldilocks principle. Available at: https://en.wikipedia.org/wiki/ Goldilocks_principle. Accessed October 2018.

2. Mazer CD, Whitlock RP, Fergusson DA, Belley-Cote E, Connolly K, Khanykin B, et al; TRICS Investigators and Perioperative Anesthesia Clinical Trials Group. Six-month outcomes after restrictive or liberal transfusion for cardiac surgery. N Engl J Med. 2018;379:1224-33.

3. Mazer CD, Whitlock RP, Fergusson DA, Hall J, Belley-Cote E, Connolly K, et al; TRICS Investigators and Perioperative Anesthesia Clinical Trials Group. Restrictive or liberal red-cell transfusion for cardiac surgery. N Engl J Med. 2017;377:2133-44.

4. Brown CH IV, Savage WJ, Masear CG, Walston JD, Tian J, Colantuoni E, et al. Odds of transfusion for older adults compared to younger adults undergoing surgery. Anesth Analg. 2014;118:1168-78.

5. Koch CG, Sessler DI, Mascha EJ, Sabik JF III, Li L, Duncan AI, et al. A randomized clinical trial of red blood cell transfusion triggers in cardiac surgery. Ann Thorac Surg. 2017;104:1243-50.
6. Murphy GJ, Pike K, Rogers CA, Wordsworth S, Stokes EA, Angelini GD, et al; TITRe2 Investigators. Liberal or restrictive transfusion after cardiac surgery. N Engl J Med. 2015;372:997-1008. Erratum in: N Engl J Med. 2015;372:2274.

7. Nakamura RE, Vincent JL, Fukushima JT, de Almeida JP, Franco RA, Lee Park C, et al. A liberal strategy of red blood cell transfusion reduces cardiogenic shock in elderly patients undergoing cardiac surgery. J Thorac Cardiovasc Surg. 2015;150:1314-20.

8. Hajjar LA, Vincent JL, Galas FR, Nakamura RE, Silva CM, Santos MH, et al. Transfusion requirements after cardiac surgery: the TRACS randomized controlled trial. JAMA. 2010;304:1559-67.

9. Berwick DM. Avoiding overuse - the next quality frontier. Lancet. 2017;390: 102-4.

10. Bennett-Guerrero E, Zhao Y, O’Brien SM, Ferguson TB Jr, Peterson ED Gammie JS, et al. Variation in use of blood transfusion in coronary artery bypass graft surgery. JAMA. 2010;304:1568-75.

11. Society of Thoracic Surgeons Blood Conservation Guideline Task Force; Ferraris VA, Brown JR, Despotis GJ, Hammon JW, Reece TB, Saha SP, et al. 2011 update to the Society of Thoracic Surgeons and the Society of Cardiovascular Anesthesiologists blood conservation clinical practice guidelines. Ann Thorac Surg. 2011:91:944-82.

12. Likosky DS, FitzGerald DC, Groom RC, Jones DK, Baker RA, Shann KG, et al. Effect of the perioperative blood transfusion and blood conservation in cardiac surgery clinical practice guidelines of the Society of Thoracic Surgeons and the Society of Cardiovascular Anesthesiologists upon clinical practices. Anesth Analg. 2010;111:316-23.

13. Berwick DM, Hackbarth AD. Eliminating waste in US health care. JAMA. 2012 307:1513-6.

14. Stokes EA, Wordsworth S, Bargo D, Pike K, Rogers CA, Brierley RC, et al TITRe2 Investigators. Are lower levels of red blood cell transfusion more costeffective than liberal levels after cardiac surgery? Findings from the TITRe2 randomised controlled trial. BMJ Open. 2016;6:e011311.

15. Loor G, Rajeswaran J, Li L, Sabik JF III, Blackstone EH, McCrae KR, et al. The least of 3 evils: exposure to red blood cell transfusion, anemia, or both? J Thorac Cardiovasc Surg. 2013;146:1480-7.e6.

16. Koch CG. Tolerating anemia: taking aim at the right target before pulling the transfusion trigger. Transfusion. 2014;54(10 Pt 2):2595-7. 